\title{
Contactless Measuring Device for Checking the Qualitative Parameters of Bead
}

\author{
Martin Bezák 1,2*, Mikuláš Hajduk ${ }^{1}$, Rudolf Jánoš ${ }^{1}$, Marek Sukop ${ }^{1}$, Ján Semjon ${ }^{1}$, Jozef Varga ${ }^{1}$, \\ Peter Duchovič ${ }^{2}$, Ivan Zajačko ${ }^{3}$ \\ TUKE - Technical University Košice, Faculty of Mechanical Engineering, Letná 9, 04200 Košice, Slovak Republic \\ VIP0 a.S., Gen. Svobodu 1069/4, 95801 Partizánske, Slovak Republic \\ 3 UNIZA - University of Žilina, Faculty of Mechanical Engineering Univerzitná 8215/1, 01026 Žilina Slovak Republic
}

Abstract: IThis article deals with development of contactless measuring device for measurement of geometric and qualitative parameters of semi product for tire - bead. Due to the current measurement and evaluation methods in series production, this equipment represents a technical and technological improvement in the tire manufacturing process. This solution excludes potential influence of process or operator during measurement or evaluation parameters. The device uses the latest knowledge and components used in industry, automation and electrical engineering as well. The designed device is immediately applicable globally as an autonomous device. Its modification also enables integration into a fully automatic process of production of tire semi-product - bead by manipulation devices. The measured parameters allow iteration and necessary set up between production process and measuring device in the future.

Keywords: Bead, Non-contact sensors.

\section{Introduction}

At present, many industries require a high level of control, evaluation and optimization of processes that affect the final result of the product. In order for the final product to be eligible, it is necessary to ensure that the individual sub-processes also meet this requirement. Such a case is also the bead, which is one of the basic building sub components of an industrial tire. The tire is generally subject to considerable demands in terms of safety, ecology, economy and comfort.

\section{Basic Tire Description and Types of Foot Beads}

Tire bead - Its purpose is to transfer engine torque and braking from the bead / disc to the contact surface of the tire with the road. At the same time, it guarantees a firm seating of the tire on the rim, where the main part is a steel bead with a core, around which the edges of the cord inserts of the carcass are bent, Fig. 1. Together with the sidewall, they are the most stressed part of the tire / tire.

Bead - is a part of every standard tire in the bead area. It is located one piece of bead on each side of the tire. It is created by the process of winding rubberized steel wire according to defined specifications. Depending on the type of tire, the bead may have a hexagonal, pentagonal, circular or rectangular cross-section. In the world, the marking of beads according to the inner diameter in inches with an additional value in $\mathrm{mm}$ has been used. Another characterized parameter is the number of windings, specification of the width and height of the bead, the diameter of the non-rubberized and rubberized wire, the angle of the bead taper base. The following types of beads are used in standard tires, which include passenger, light truck, truck and bus, agricultural 
and industrial tires, Fig.2.

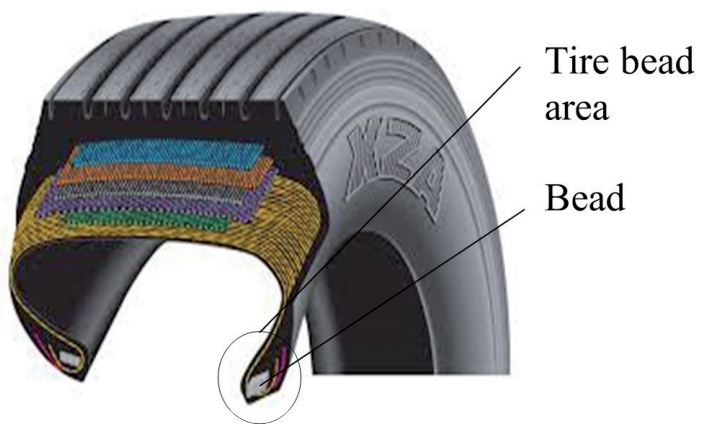

Figure 1: Passenger tire cross section

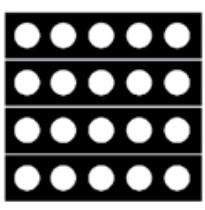

A

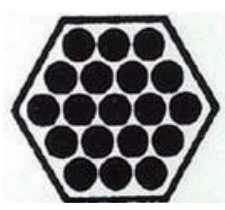

B

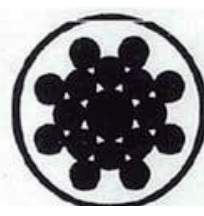

C
Figure 2: Basic types of beads use in tires

\section{Production of Foot Bead}

The device for the production of a bead is called a single-wire single head or multi-wire bead winding line for winding the bead. The line is composed of one unit of individual devices, which are connected into one system with own control system. This machine is usually operated by one operator, whose main task is to control and monitor the production process and prepare inputs raw materials - steel wire and rubber compound. At the same time, it operates the supply system of finished beads, either by storing them in trolleys or loaded into trolleys directly in a fully automated process. The device consists of the following units, fig. 3:

\section{Unwinding station}

2.Wire welding unit

3. Contactless wire preheating

4. Rubber compound feeding conveyor

5. Extruder with tempering stations

6. Festoon for rubberized wire and cooling drums

7. Winding station

8. Bead removal manipulator

9. Storage system of finished beads

As there may be various variations in the manufactured product in the process, which are caused by:
"By setting up the machine
"Wear contact parts of the device

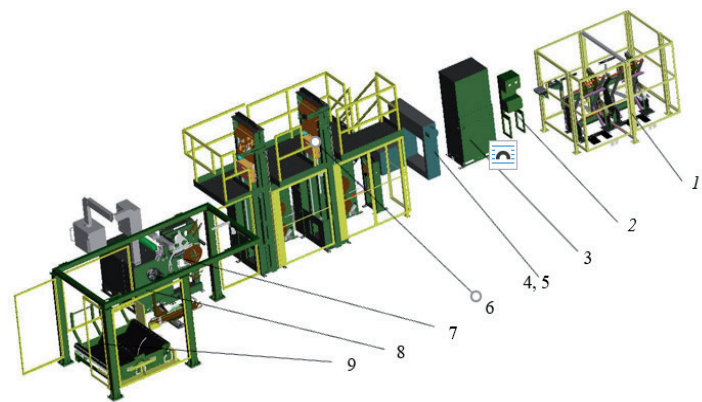

Figure 3 - 3D model of Equipment for production hexagonal bead

It is necessary to control the process and product during production to meet quality requirements. For this purpose, tire manufacturers use various methods to check the physical parameters of the bead.

Among the basic indicators, resp. the geometric parameters that are evaluated during the production of the bead include:

1. Inner diameter of the bead

2. Inner circumference of the bead

\section{Bead height}

4. Bead width

5. Bead compactness

6.Bead weight

7. Bead ovality

8.Initial and final position of the bead wire

9. Offset of the beginning and end of the bead wire

10. Bead taper bead angle

11. Bead flatness

12. Opening the ends of the wounded wires

13. Rubber coating correctness

14. The size of the weld in the bead

15. Number of welds in the bead

There is requirement of producers to automatized control process and record the measurement results.

" integrate bead parameters measurements into one device

" streamline this process and prevent possible operator error

" continuously or online evaluate product parameters and record results

" to integrate the evaluation measurement process into the production process with possible control of the bead production process by feedback

" preferred non-contact measurement without affecting the product geometrically or by changing parameters

These requirements of tire manufacturers require a high level of equipment for measuring the parameters of the bead, as several measurements 
are integrated in one device with high accuracy and repeatability of the measurement process.

Many manufacturers of machinery for the production of semi-finished tires come to the market with a combination of two resp. three measurements in one device. A complex device that could evaluate all the required measurements on one device is practically not available yet.

\section{Design of Equipment for Measurement and Evaluation of Measured Sleeve Bead Parameters}

The concept of the solution of a non-contact measuring device was decided to respect requirements for major measuring parameters, include possibility of full process automation and manipulation with product. As an optimal solution for non-contact measuring device was recognized system using sensors and cameras which have no impact on results

To ensure the requirement for the integration of the measurement of the bead quantities in one device, this device was designed to be fully autonomous with the potential for integration with the bead production device. Measured parameter and method:

1. Inner diameter of the bead - measurement by optical sensors

2. Inner bead circumference - measurement by optical sensors

3. Bead height - measurement by optical sensors

4. Bead width - measurement by optical sensors

5. Bead weight - measurement with strain gauges

6. Bead ovality - measurement by optical sensors

7. Initial and final position of the bead wire - measurement by optical sensors

8. Offset of the beginning and end of the bead wire - measurement by optical sensors

9. Angle of the bead taper base - measurement by optical sensors

10. Offset of the beginning and end of the bead wire - measurement by optical sensors

The design of the measuring device is designed in two variants:

The first design concept - the device for measuring the parameters of the bead considers the use of 8 laser profilometers arranged in a circle with a spacing of $45^{\circ}$, Fig. 4. The solution can be supplemented with additional sensors and thus obtain more accurate information about the waving of the inner circle. The advantage of the device designed in this way is the high accuracy of the measurement, which depends in particular on the sensor accuracy, since there are no moving parts. The measurement time is relatively short, especially if parallel measurement is used on all sensors. However, when evaluating the solution from a commercial point of view, this version was not evaluated as optimal due to the use of 8 laser sensors, which would significantly increase the price of device.

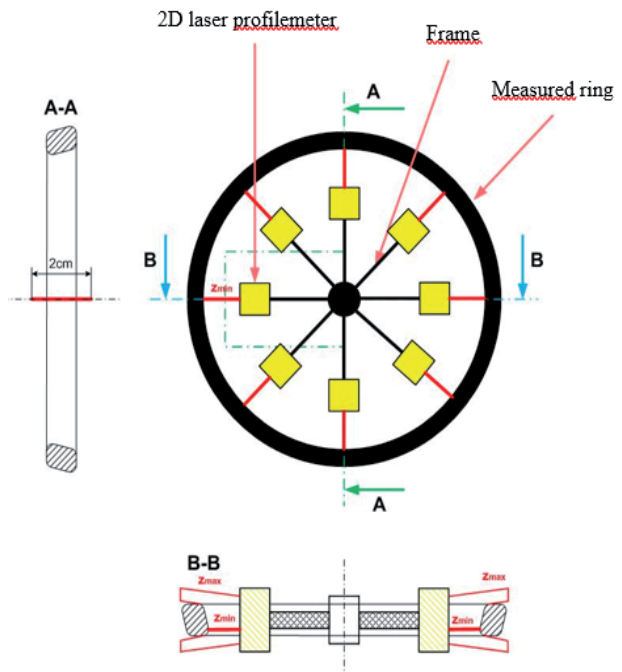

Figure 4: Basic design concept I. of Equipment

The second design concept - the profilometer is positioned to measure the inner diameter of the bead in the z-axis, where it has the highest possible accuracy, fig. 5. The profile measurement is always parallel to the central axis of the measured ring. With this measuring principle, the measuring error is increased by the sensor positioning error. During the measurement, the sensor moves by rotating around the centre in the swivel joint. An absolute rotation sensor is also mounted in the swivel joint, which can be used to monitor the position of the profilometer. The profilometer control unit is set to evaluate the smallest distance of the measured profile in the z-axis ( $z$ min). The width of the profile measurement depends on the measured distance but is usually around $20 \mathrm{~mm}$ for profilometers with the required accuracy.

The measuring speed can be increased by increasing the number of lasers profilometers to 2 pieces, where the profilometers would be firmly connected with a spacing of $180^{\circ}$, or by increasing the profilometers to 4 pieces where the spacing between them would be $90^{\circ}$. However, these options will again significantly increase the final price of the device. 


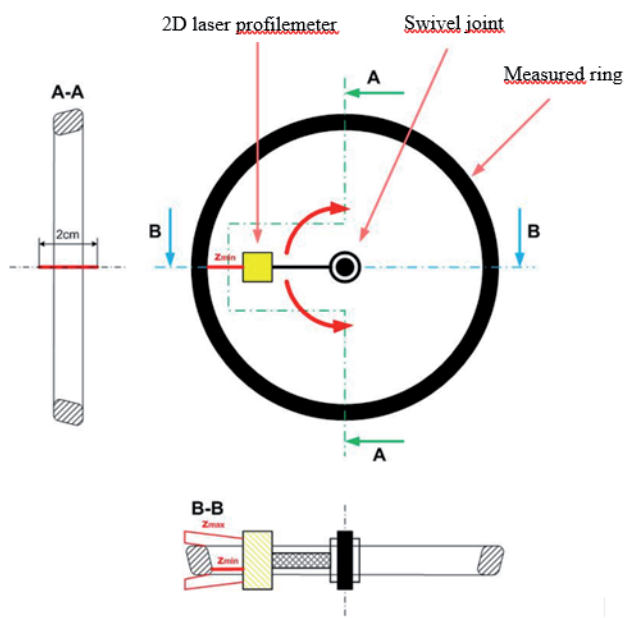

Figure 5: Basic design concept II. of Equipment

Requirements for measured bead parameters:

\section{Bead inner circumference - bead tolerance $\pm 0.8 \mathrm{~mm}$}

2. Bead inner diameter - bead tolerance $\pm 0.2 \mathrm{~mm}$

3. Roundness / Ovality - bead tolerance $\pm 3 \mathrm{~mm}$

4. Bead height - bead tolerance $\pm 0.3 \mathrm{~mm}$

5. Bead width - bead tolerance $\pm 0.3 \mathrm{~mm}$

6. Wire joint offset - bead tolerance $\pm 10 \mathrm{~mm}$

7. Bead weight - bead tolerance $\pm 1 \mathrm{~g}$

\section{Joint sensing}

9. Sensing the position of the wire ends and measuring the length of the offset

10. Sensing the area of the non-rubberized surface of the bead

\section{Sensing the angle of the base of the bead}

The measurement of all parameters must not exceed a cycle time of $30 \mathrm{sec}$. Including time for inserting and removing the bead into the measuring device.

A prototype design of the device for non-contact measurement of bead values is shown in Fig.6.

The basic construction of the prototype device consists of a construction of duralumin profiles connected by screw joints with a closed transparent PMMA as a covering. The drive of sensors moving holder in the vertical direction is mounted separately on the frame. The movement is done by a pneumatic cylinder mounted on a bracket which is firmly mounted on the frame of the device. The upper position of the holder with sensors allows insert the bead, by operator or handling equipment. The lower position is intended for the measurement process. The transverse movement of the laser profilometer holder is ensured by a servomotor according to the specified dimension of

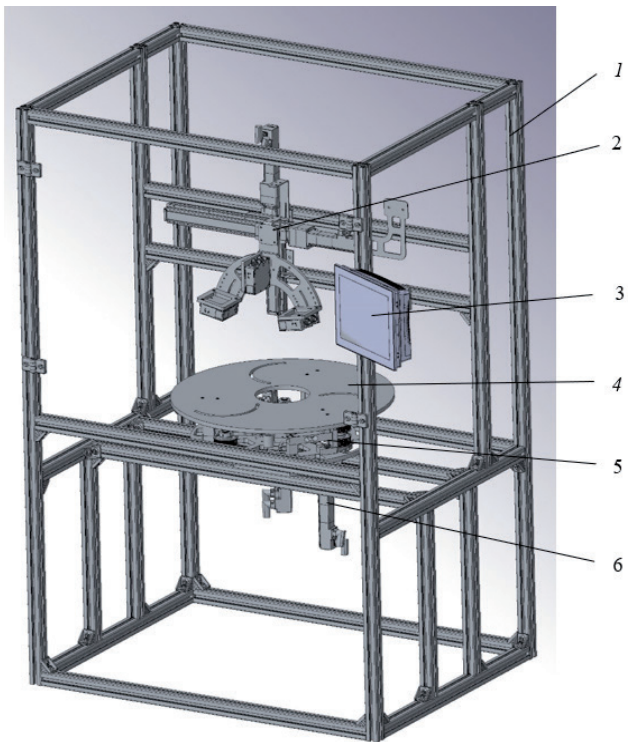

1 - basic frame of Equipment, 2 - stroke of sesnors holder , 3 - sensors holder, 4 - main Equipment panel, 5 - table for bead positioning, 6 table position on tenzometers, 7 - drive for table rotation with bead Figure 6: Prototyp design model of Contactless measuring Equipment for bead parameters

the measured bead. The rotary table with a drive for positioning of the bead is in bottom part of device. The bead itself is positioned on the table, which is set on three holders in a horizontal position with tensometers for measuring product weight. The correct positioning and centering of the bead in a horizontal position against to the sensors is ensured by pneumatic pin drives located on the turntable. The rotation of the table with the bead is in the range of $380 \div 400$ degrees and is provided by drive located bottom section of the device. The device is controlled by own control system and an operator panel is located on the outer side of the device. The electrical elements and components are mounted on individual parts of the device and connected to the main control panel by wires. The pneumatic hoses are distributed supplied with compressed air from the main pneumatic unit on the machine.

A view of the mounting of the bead is shown in Fig. 7.

Connection diagram of device with PC for storage and evaluation measured parameters is shown in Fig. 8.

There is requirement to make a calibration of device before the measurement process itself. The process is done by using of calibration steel 


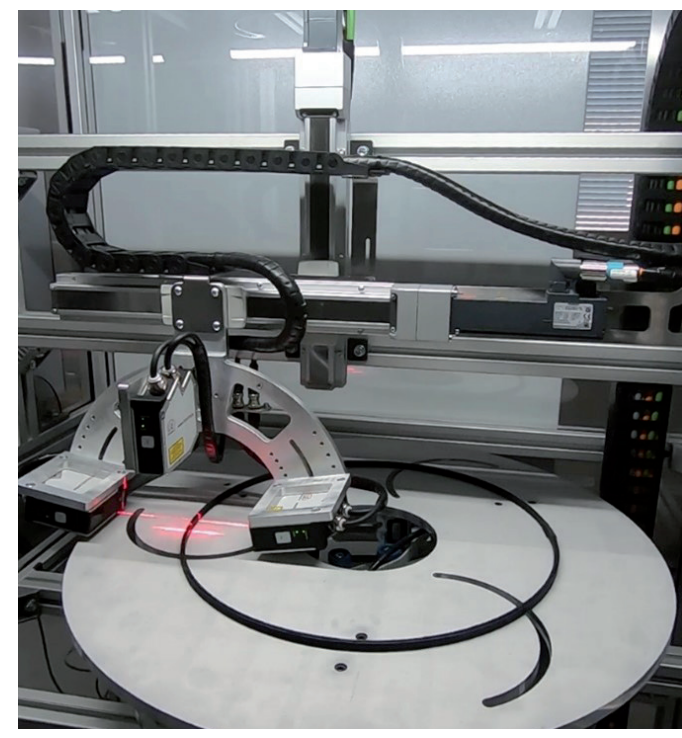

Figure 7: Main view on positioned bead

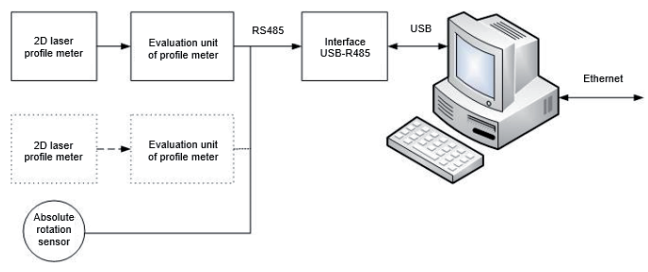

Figure 8: Diagram of Equipment connection with PC for collection of measured data

ring, which the operator inserts on the holders and selects the "CALIBRATION" function on the control panel. The calibration ring has a defined shape and is intended for setting the device. It is a necessary part of the machine and supplied by the manufacturer. The device hereby sets the positions for the sensors to the zero position. The device can be used in production to evaluate products from multiple machines, but it is necessary for the operator to choose the correct product type and use login codes for the device.

Based on the measurement results of parameters and quantities, these values are displayed on the operator panels. Subsequently, these will be compared with the entered values and their tolerances. The results are display on panel as curves of previous measurements in graphs and the values of the competency coefficient of the cpk process will be calculated.

In practice, several types of Process Capability Indexes (Cp, Cpk, Cpm) are used to evaluate process capability. These differ in the method of calculation, properties, and usability conditions. It is the ratio of the required accuracy and the achieved accuracy of the monitored quality indicator in the production process. It is a dimensionless number and the higher the value, the more favourable the production process.

This assessment is importantfor the manufacturer as it serves to estimate the likelihood of nonconforming products and thus to plan preventive and corrective measures and thus to monitor the stability of the process. This value is also important for the customer who receives information on whether the quality requirements have been met and the product has been manufactured in stable conditions.

\section{Index Cp}

The Cp capability index is the ratio of the maximum allowable variability of USL - LSL values

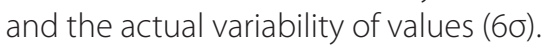

$$
C_{p}=\frac{\mathrm{USL}-\mathrm{LSL}}{6}
$$

USL - (Upper Specification Limit) upper tolerance limit, LSL - (Leader Specification Limit) lower tolerance limit, $\sigma$-standard deviation of the process, speaks to the extent to which the process is able to be in the tolerance band. However, it does not talk about where it is in this band.

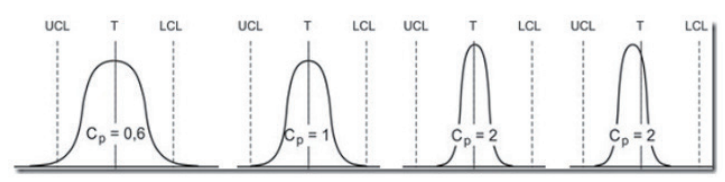

Figure 9: Dipspaly of capability index $C p$

\section{Index Cpk}

The critical competency index Cpk takes into account not only the variability of the monitored quality characteristic, but also its position in the tolerance field. It can also be used if the tolerance fields are not symmetrical.

$$
C_{p k}=\min \frac{(U S L-\bar{x})}{3 \sigma} ; \frac{(\bar{x}-L S L)}{3 \sigma}
$$

In practice, the potential capability of the process in the upper or lower relationship between:

Cpk (USL) - potential process capability in relation to the burned tolerance between USL or Cpk (LSL) 
- potential process capability in relation to the lower tolerance between LSL.

$$
C_{p k(U S L)}=\frac{(U S L-\bar{x})}{3 \sigma} ; C_{p k(L S L)}=\frac{(\bar{x}-L S L)}{3 \sigma}
$$

Process capabilities are mostly related to the capability index value Cpk, which is relative to the position relative to the mean value. According to the value of Cpk, we can divide the process into:

Cpk $<0$, the process is centered outside the tolerance limits,

Cpk $=0$, the process is centered on one of the tolerance limits,

Cpk $<1$, it is an ineligible production process - a process unable to comply with the prescribed values,

Cpk $\leq 1.25$, the production process is well suited for common products,

Cpk $\leq 1.45$, a new production process or an established production process of safety-related products is well qualified,

Cpk $\leq 1.6$, the new production process of safetyrelated products is well-qualified.

\section{Conclusion}

The main benefit is the possibility of evaluating several parameters simultaneously without the need to repeat the measurement for individual parameters. The added value of the device is the possibility of its work in the off-line mode and in the provision of the device for inserting and removing the product in the online mode of the line for the production of beads. This device offers final users a complete and compact production unit. The uniqueness lies not only in the technical solution and the possibilities of integration in the production process, but also in the number of evaluated quality parameters directly in the production process.

The measuring device for measuring and evaluating the results of measuring the parameters of a semi-finished product for tires is a unique device in Slovakia and the range and number of measured quantities in the world.

\section{References}

[1] C. Fragassa, M. Ippoliti: TECHNOLOGY ASSESSMENT OF TIRE MOULD CLEANING SYSTEMS AND QUALITY FINISHING. International Journal for Quality Research 10(3) 523-546, 2016
[2] M. SUKOP, M. HAJDUK, J. SEMJON, R. JÁNOŠ, J. VARGA, M. VAGAŠ: Measurement of weight of objects without affecting the handling algorithm, In: International Journal of Advanced Robotic Systems. Vol. 13 no. 5 (2016), p. 14-19. - ISSN 1729-8814

[3] J. VARGA, R. JÁNOŠ, M. SUKOP, M. HAJDUK, P. DUCHOVIČ, M. BEZÁK, M: Measurment of bead wire circumference via optical sensor In: Technical Sciences and Technologies. No. 4(6) (2016), p. 194-199. - ISSN 2411-5363

[4] M. Bezák: Tyre manufacturing technology / In: Tire Technology International, published October 2018 [print online].https://www.ukimediaevents.com/publication/ ed63a87d/88

[5] Safe launch manual Bead Wire, Bekaert, TCP/13/025, March 5th., 2013

[6] J. Kahn: The Fourth Revolution - Passion for High Performance, Bartell Machinery, 2020

[7] J. VARGA, M. SUKOP, R. JÁNOŠ, M. HAJDUK, P. DUCHOVIČ, M. BEZÁK: Solutions for measuring weight of bead wires In: Applied Mechanics and Materials vol. 841 : Aerospace, Robotics, Manufacturing Systems, Mechanical Engineering, Biomechatronics and Neurorehabilitations. - Switzerland: TTP, 2016 P. 145-151. - ISBN 978-3-03835-668-4

[8] SUKOP, Marek - FERENČíK, Peter: Design of intelligent robotic cell with camera system In: Technical Sciences and Technologies. - Černihiv (Ukrajina) : Chernihiv National University of Technology Roč. 17, č. 3 (2019), s. 96-104 [print]. - ISSN 2411-5363

[9] M. Bezák: Successful solutions for bead wire production In: Tyre Asia, published, Feb 1, 2019 [print, online]. (https:// tyre-asia.com/2019/02/01/successful-solutions-for-beadwire-production/)

[10] J. KOVÁČ, R. JENČ́́K, P. ANDREJKO, M. HAJDUK, Z. PILAT, P. TOMČl, J. VARGA, M. BEZÁK: Integrated Palletizing Workstation with an Industrial Robot and a Cobot, In: Advances in Service and Industrial Robotics : proceedings of the 28th International Conference on Robotics in AlpenAdria-Danube Region. - Cham (Švajčiarsko) : Springer International Publishing AG s. 202-209 [print, online]. - ISBN 978-3-030-19648-6

[11] Micro Epsilon - Compact laser scanner dataSheet 